\title{
The effect of vacuum on the mechanical properties of die cast aluminum AlSi9Cu3(Fe) alloy
}

\author{
Péter SZALVA ${ }^{*}$, Imre Norbert ORBULOV ${ }^{1,2}$ \\ ${ }^{1}$ Department of Materials Science and Engineering, Budapest University of Technology and \\ Economics, Müegyetem rakpart 3., Budapest, 1111, Hungary \\ ${ }^{2}$ MTA-BME Lendület Composite Metal Foams Research Group, Műegyetem rakpart 3., \\ Budapest, 1111, Hungary
}

\author{
*Author for correspondence: $\underline{\text { szalva@ eik.bme.hu }}$ \\ *Telephone number: +36-30-562 3912
}

*ORCID ID: 0000-0002-6562-6165

https://orcid.org/0000-0002-6562-6165

\begin{abstract}
High pressure die casting (HPDC) is a widely used casting technology for product that is made of light metal such as aluminum alloy. During die casting process the molten metal is injected into a mold at high speed and solidify under high pressure. The amount of porosity in the cast part is an important question. Lots of technologies have been developed to minimize porosities, for example, vacuum-assisted high pressure die casting process (VPDC). In this paper, AlSi9Cu3(Fe) aluminum alloy castings were produced by conventional HPDC with atmospheric venting and VPDC process under three different absolute cavity air pressures of 170 mbar, 90 mbar and 70 mbar at the cavity. The influence of absolute cavity air pressure on the porosity and on the mechanical properties of the castings were investigated and compared with conventional HPDC casting method. The results of the present study proved that the amount of porosity and the pore sizes in the castings can be significantly reduced from $1.10 \%$ at an atmospheric level to $0.47 \%$ at 70 mbar. This corresponds to $57 \%$ reduction. As a result, the mechanical properties are improved significantly, particularly, the tensile strength from 271.6 MPa to $299.8 \mathrm{MPa}$, which corresponds to $10 \%$ increment and the elongation from $1.66 \%$ to $2.49 \%$, which shows $50 \%$ increment. At lower absolute cavity air pressure the entrapped gases become the final gas porosities in the die castings and shows solidification shrinkage form inspected with scanning electron microscopy. In general, lower cavity air pressure contributes to reduce the pores, which improve the mechanical properties of die casting.
\end{abstract}

Keywords: HPDC, VPDC, mechanical properties, porosity, LOM, SEM, 


\section{Introduction}

Automakers throughout the world have been continuously working on lightweight design to produce lighter vehicles that cost less and use less fuel. The automotive market for light metal products continues to grow at an increasing rate. The weight of the vehicles had been reduced by $10 \%$, while the fuel consumption had been reduced by $6-8 \%$ from 1990 to 2010 [1]. This has been inevitably resulting in a much-increased demand for die cast aluminum product. This is because the aluminum alloys are the optimum choice for automotive parts where they offer significant advantages of lightweight, excellent processability and high corrosion resistance besides the complete recyclability [2]. The aluminum-silicon (Al-Si) and aluminum-siliconcopper (Al-Si-Cu) cast alloys are widely used in different automotive applications because of their good castability.

The selection of casting technology is critical for the mass production of die castings. One of the most frequently used technology of casting applied for aluminum alloys is the high pressure die casting (HPDC), which is a near net shape technology. The process ensures high surface smoothness and excellent dimensional and shape accuracy for the castings. HPDC is a highly productive manufacturing process. The cycle time for small parts cast in multi-cavity tool can be a few seconds, and even large parts only about one minute [3]. During die casting process the molten metal is injected into a metal mold at high speed and solidify under high pressure [4]. The applications of aluminum die casting are not limited to powertrain components. Die casting is also capable of producing structural components, which require heat treatment or welding.

In cold chamber aluminum die casting process gas is often trapped in the metal [5], and creates internal gas porosities of casting due to high filling turbulence at the high metal injection speed. Filling turbulence and its resultant air porosities have a negative impact on the mechanical properties. For this reason, mold design directly affects the quality of the castings [6]. Furthermore, the spraying liquid may be vaporized to create additional moisture gas. This phenomenon can cause porosity in the casting as well, which have a negative impact on the mechanical properties of the product [7]. The porosities can act as stress concentrators or stress raisers. An additional challenge is the fact that porosity in a casting may not be immediately detected after die cast, but only revealed during subsequent processing such as welding or heat treatment. One possible solution to reduce the amount of gas in the die cavity is vacuum assistance [8]. Vacuum-assisted die casting (VPDC) were introduced into cold chamber die casting process in this present work.

The HPDC process is start with melting of the metal in a separate furnace. The precise amount of molten metal is transported to the cold chamber casting machine where it is fed into an unheated injection cylinder. The shot is then driven into the die by a hydraulic plunger movement. This process is divided into three main phases (Fig. 1.). The fed liquid metal reaches the in-gate system at the end of the first phase. During the second phase this molten metal is fill the die cavity. Finally, the mold cavity is filled and the intensification pressure is maintained until the casting solidifies in the third phase. During solidification the cavity is pressurized by the plunger to feed the solidification shrinkage. 
The vacuum-assisted die casting process is introduced via a vacuum valve with a vacuum

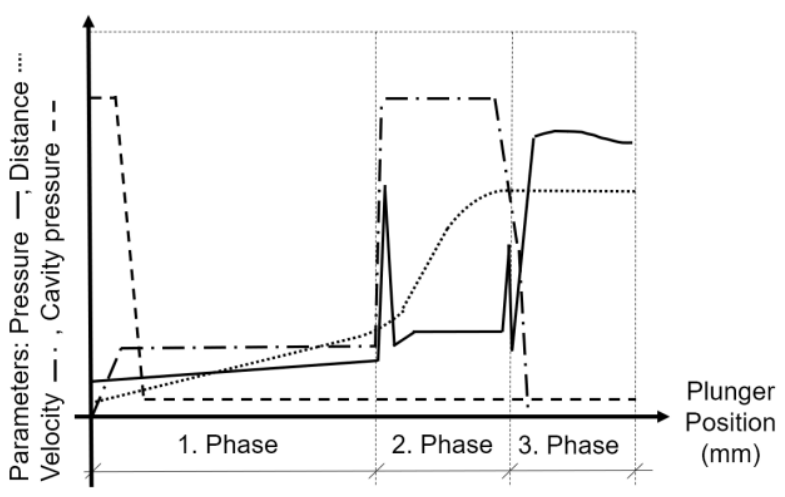

Fig. 1. Phases of vacuum-assisted high pressure die casting.

Almost all of the air, steam and other gases are evacuated from the mold. The low pressure in the mold cavity enables the molten metal to flow into blind recesses [10]. The sufficient vacuum allows the fronts of the molten metal to merge freely without forming cold shuts due to the lack of air.

In this study, the effectiveness of the vacuum-assisted method to improve the mechanical properties of the castings were investigated by the two-parameter Weibull analysis [11]. In addition, the effect of the cavity pressure on the porosity of the casting was also investigated with scanning electron microscopy (SEM) and light optical microscopy (LOM). During experiments the material chemical composition was the same and the casting process parameters were fixed, only the vacuum-assisted process parameter (absolute pressure in the cavity) was changed during the experiment.

\section{Experimental and Investigations}

\subsection{Die casting material}

The experiments were performed with AlSi9Cu3(Fe) (EN AC 46000, 383.0) casting aluminum alloy. The actual and nominal chemical composition of the melted aluminum is tabulated in Table 1. This grade of aluminum alloy is widely used because it is a relatively cheap casting material. However, the Authors have to note that this alloy has not been extensively examined from vacuum-assisted die casting point of view. Another reason for choosing this alloy is its favorable mechanical properties. These favorable mechanical properties are due to its silicon and relatively high copper content, which provides the possibility of precipitation hardening. In this way, the favorable strength values can be further increased by heat treatment. The aluminum ingots were melted in a gas heated furnace. The liquid aluminum was treated with rotary degassing with nitrogen gas for 6 minutes. During the casting of the test pieces one heat was used, which was dosed with automatic ladling from a resistance heated holding furnace.

Table 1. Chemical composition of AlSi9Cu3(Fe) [12] 

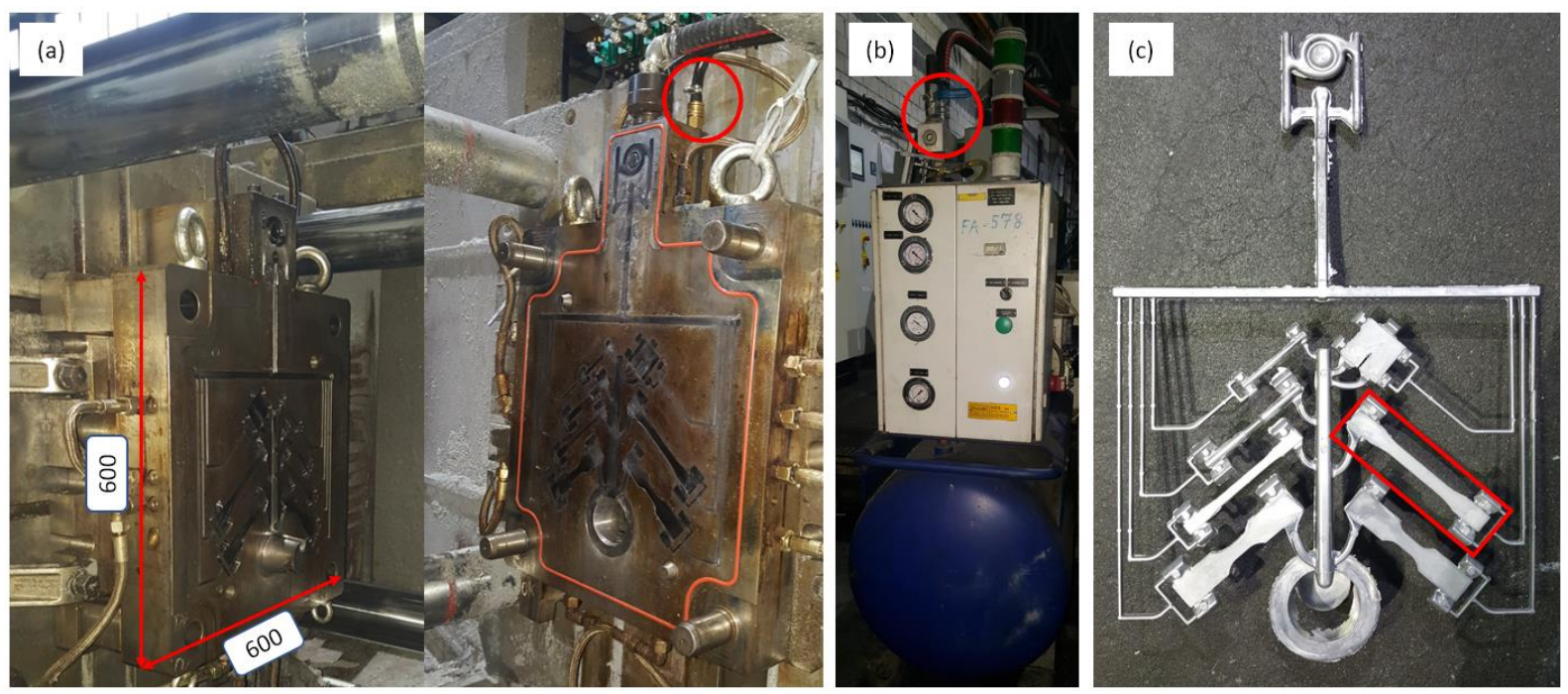

Fig. 2. Die tool and the vacuum system: (a) vacuum valve and their connection; (b) vacuum unit; (c) the casting bunch. 


\subsection{Key die casting process parameters}

The conventional casting process was performed firstly. During the die casting process the adjusted pressure was atmospheric in case of conventional HPDC and chill blocks vents were installed in both halves of die frame. The summarized in-gate system cross section was 136 $\mathrm{mm}^{2}$, the venting channel cross section was $33 \mathrm{~mm}^{2}$ at the common channel section. The vacuum valve was mounted to the top in the VPDC trial phases. The VPDC were performed at three different absolute cavity air pressures of $170 \mathrm{mbar}, 90 \mathrm{mbar}$ and $70 \mathrm{mbar}$, respectively. 40 shots were made at each pressure levels and the first 3 shots were immediately discarded for quality reason. The tests were done at the following set-up process parameters: liquid metal temperature of $710^{\circ} \mathrm{C}$, die tool temperature of $180^{\circ} \mathrm{C}$ maintained by oil temperature control units, total volume of cast bunch with gating and venting system of $289.3 \mathrm{~cm}^{3}$, plunger tip diameter of $60 \mathrm{~mm}$, the plunger velocity during first stage was $0.5 \mathrm{~m} / \mathrm{s}$, while during the second stage it was set to $2.8 \mathrm{~m} / \mathrm{s}$, the third phase intensification pressure was 704 bars and clamping force $3800 \mathrm{kN}$ was applied. The die tool temperature was controlled by the Tool-Temp TT-288 oil circuit temperature control unit (TCU). The total length of the shot sleeve was $350 \mathrm{~mm}$, the plunger tip extends into the sleeve by $52.5 \mathrm{~mm}$, the first stage length was $194 \mathrm{~mm}$, the second stage length was $62 \mathrm{~mm}$ and the intensification path length was $5.3 \mathrm{~mm}$, the rest of the total length was the thickness of the biscuit. The total air volume to evacuate was $289.3 \mathrm{~cm}^{3}$ in the die and $517 \mathrm{~cm}^{3}$ in the chamber in case of $39 \% \mathrm{~F}$ filling degree. The plunger velocity in the first stage depends mainly on the state of the developing fluid wave in the shot sleeve before the beginning of the injection stage [13]. The velocities of different stages were determined by filling simulation. The vacuum applied to the die tool across the shot sleeve after the plunger tip passes the pour hole. Therefore, accompanied with the casting parameters, after the plunger tip seals the pour hole, about 0.250 seconds required to achieve the desired vacuum level. In other words, during this time period, which $\sim 250 \mathrm{~ms}$, the air pressure in the die cavity is reach the required level from atmospheric pressure level. The specimens were tested in ' $\mathrm{F}$ ' as-cast condition, which means controlled cooling in water after the ejection and natural aging at room temperature [12]. The mechanical test was performed 8 days after production, after the total natural aging of the specimens. Other factors that affect product quality are the mold temperature, molten metal temperature and the speed of the injection stages, that is the why, these parameters were fixed during experimental samplings [6].

\subsection{Die casting test specimen}

The mechanical properties of structural die casting parts strongly vary from one area to another, that is why the inspected casting is a small volume cast-to-shape part [14]. The tensile strength of castings was measured on an Instron 5985 testing machine supported with extensometer gauge at room temperature (Fig. 3.). The applied tensile rate was $1 \mathrm{~mm} / \mathrm{min}$. The gauge length was $\mathrm{L}_{0}=50 \mathrm{~mm}$. The investigated specimen was trimmed from the bunch, so it was in cast-to-shape condition. 


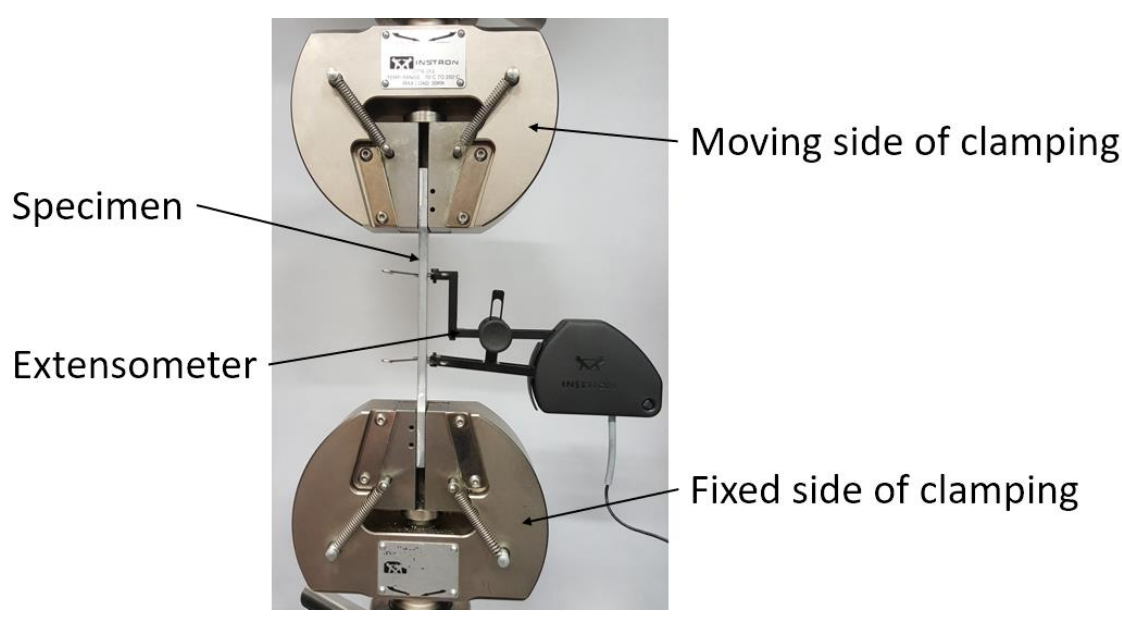

Fig. 3. Testing environment for tensile test.

The mechanical properties were measured on cast-to-shape flat tensile specimens, without further machining (except the trimming and grinding of the burrs). The results were evaluated according to the standard ISO 6892-1:2016 [15], the dimension of the specimen class D ( $a \geq 3$ $\mathrm{mm}), 13 \mathrm{~mm} \times 5 \mathrm{~mm}$ cross-section (Fig. 4.), the testing method was method B.

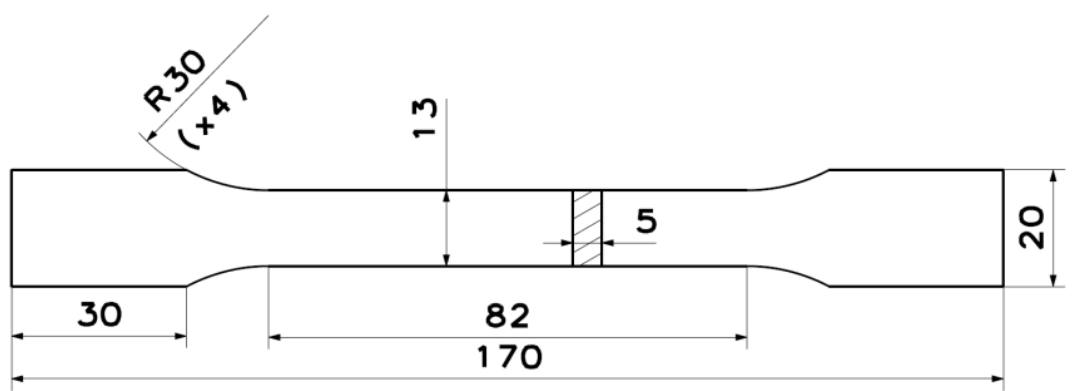

Fig. 4. The dimensions of the cast flat test piece.

The corners of the cross-section of cast flat specimen are act as stress raisers against the round cross-section homogeneous stress distribution. The cross-section has rounded corners of $0.2 \mathrm{~mm}$, and the draft angle was taken into account at the cross-section calculation. The burrs of the parting line were completely removed before the test with a trimming tool. The rest of the burrs were removed, the finishing was grinding. The casting bunch is consisting of seven different test specimens. The reason of the chosen flat specimen for the uniaxial tensile test is the thickness and the shape. This is the best representation for an investigated specific structural component at the foundry, where the study was taken.

\subsection{Die casting quality evaluation}

The porosity of castings was estimated by the precise measurement of the density of small sample method [16]. Hydrostatic weighting was carried out [17]. All specimens were weighted in the air and in water as well [18], and their densities were determined according to the following equation [19] (Eq. 1.):

$$
\rho_{s}=\frac{m_{1}}{m_{1}-m_{2}} \rho_{w}
$$


where $\rho_{s}$ is the density of specimen $\left(\mathrm{gcm}^{-3}\right), \rho_{w}$ is the density of water $\left(\mathrm{gcm}^{-3}\right), m_{l}$ is the mass of the specimen $(\mathrm{g})$ in the air and $m_{2}$ is the mass of the specimen $(\mathrm{g})$ in water.

The density of specimen $\rho_{s}$ takes the porosity into account. Hence, the porosity of the examined specimen can be calculated with the following equation (Eq. 2.):

$$
P=\left(1-\frac{\rho_{s}}{\rho_{A l}}\right) 100 \%
$$

where $P$ is the porosity $(\%), \rho_{s}$ is the density of the specimen $\left(\mathrm{gcm}^{-3}\right), \rho_{A l}$ is the true density of AlSi9Cu3(Fe) $\left(2.75 \mathrm{gcm}^{-3}\right)$ according to EN1706 [20] and $\rho_{w}$ is the density of water at $20^{\circ} \mathrm{C}$ $\left(0.998 \mathrm{gcm}^{-3}\right)$ according to ITS-90 [21].

The specimens were pre-inspected with X-ray analysis before the tensile test. The size and the distribution of both the porosity [22] and shrinkage [23] were inspected according to ASTM E505 [24]. X-ray is one of the best testing methods to investigate the porosity, shrinkage, and foreign material content of the castings [25]. The X-ray inspection can be used to detect large pores. However, this method has a limitation, the minimum size of the detectable porosity. The detectable minimum defect size was $0.2 \mathrm{~mm}$, which sets the lower limit of the quantitative evaluation. According to the biggest measurement and the distribution of pores and shrinkages and sample thicknesses the results were Level 1 due to vacuum assist, which means good results. That is why, the results were used for pre-assessment of inclusion, shrinkage and porosity control. Foreign materials were not detected in the inspected casting set. Aluminum oxide was detected on the fracture surface in a few samples [26]. But, because of the nature of the aluminum oxide it cannot be detected in the casting with X-ray. The samples, which contains aluminum oxide on the fracture surface have been excluded from the evaluation, because of the scope of the present study is focused on the porosity type of inhomogeneities rather than any other casting defects. The inhomogeneities were examined on Yxlon MU2000 $\mathrm{X}$-ray machine. The microstructures were analyzed using light optical microscopy (LOM) by Olympus BX51M. The fracture surfaces were examined with scanning electron microscopy (SEM) [27] equipped with an energy dispersive X-ray analyser (EDX) [28] by Zeiss Evo MA15 SEM machine $(E H T=20.00 \mathrm{kV})$, to prove the presence of porosities.

\subsection{Mechanical property analysis}

The mechanical properties were assessed by Weibull analysis. Scatter of mechanical properties has been a common problem with castings. The quality of the castings and the properties of casting material are not easily reproducible [11]. The common approach to deal with scatter is simply to take an average, in this situation the standard deviation can be also calculated. But if one keep all results, and plot them to reveal their distribution, one can obtain a curve such as in (Fig. 5.). 

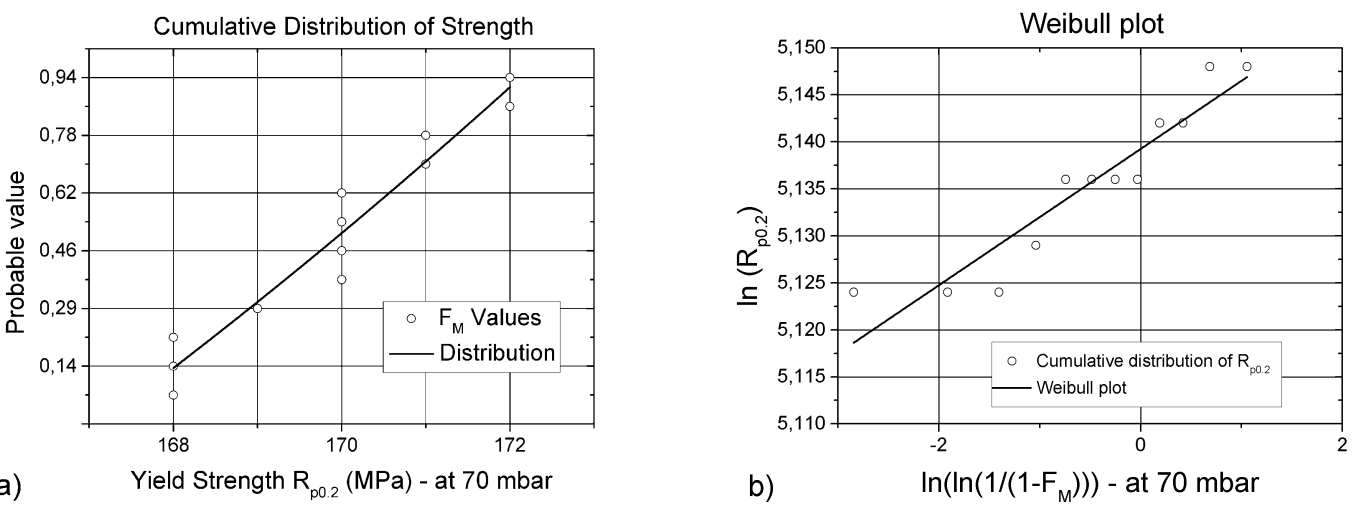

Fig. 5. a) Cumulative distribution of strength and, b) Weibull plot of the data.

The form of the distribution curve is illustrated as in Fig. 5b. The $F_{M}$ value means the median rank, which is dimensionless [29]. The $\mathrm{F}_{\mathrm{M}}$ can be determined with the following equation (Eq. 3.):

$$
F_{M}=\frac{\mathrm{i}-0.3}{\mathrm{TN}+0.4}
$$

where $F_{M}$ is the median rank, $i$ is the 'th' specimen, $T N$ is the total number of the test bars in the evaluated series.

The Weibull plot [8] is another way of presenting a cumulative distribution (CD) of data. The shapes of the Weibull plots are a measure of the reproducibility of the data. Fig. 6. shows Weibull plots for a single AlSi9Cu3(Fe) alloy with atmospheric and three different vacuumassisted levels.

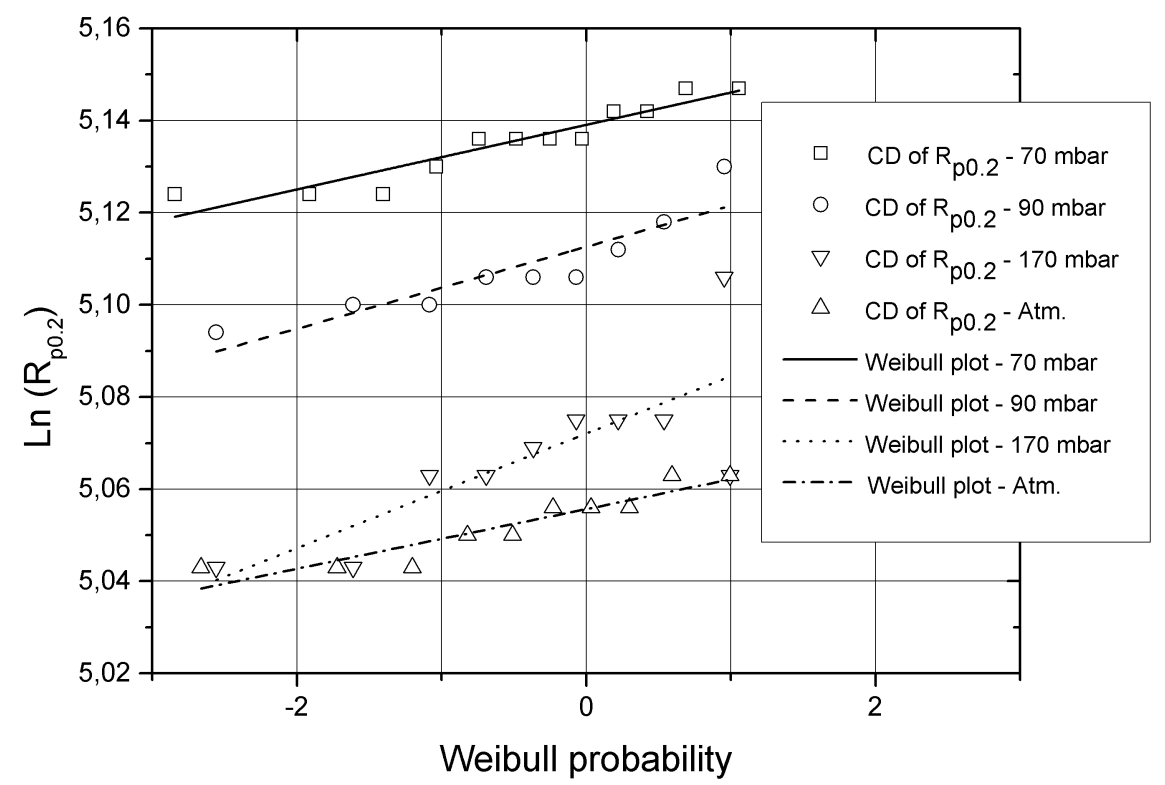

Fig. 6. Weibull plot of yield strength $\mathrm{R}_{\mathrm{p} 0.2}$ for $\mathrm{AlSi} 9 \mathrm{Cu} 3(\mathrm{Fe})$ alloy in various vacuum-assist ( $\mathrm{CD}=$ cumulative distribution). 
The variety of pressure showing the variation in reproducibility between different pressure

\section{Results and Discussion}

\subsection{The effect of vacuum assistance on porosity}

The AlSi9Cu3(Fe) aluminum alloy cast specimens were produced by conventional die casting process under atmospheric pressure and vacuum-assisted casting processes under three different absolute die cavity air pressures of $170 \mathrm{mbar}, 90 \mathrm{mbar}$ and $70 \mathrm{mbar}$, respectively. 20 pieces of casting specimen were pre-examined at each pressure level with X-ray method [32]. The parts quality based on the ASTM E505 from porosity and inhomogeneities point of view were good. The good result means that foreign materials, shrinkage and porosity were not detected in the inspected casting set. Therefore, 15 pieces were randomly chosen for the investigation. It was found that the porosity in the castings was not eliminated even with the vacuum assistance, but the total amount of porosity reduced by one third compared to the conventional die casting [33].

The densities of the castings were measured by hydrostatic weighting on both the HPDC and VPDC specimens. The results of the density measurements are detailed in Table 2. The effect of the vacuum assistance on the porosity shows homogeneous distribution based on the X-ray images.

Table 2. Pressure levels and porosity contents by Averaging

\begin{tabular}{|c|c|}
\hline Pressure (mbar) & Porosity by Averaging (\%) \\
\hline 70 & 0.47 \\
\hline 90 & 0.67 \\
\hline 170 & 0.71 \\
\hline Atmospheric & 1.10 \\
\hline
\end{tabular}

The averaged results were plotted as a porosity versus pressure diagram (Fig. 7.). 


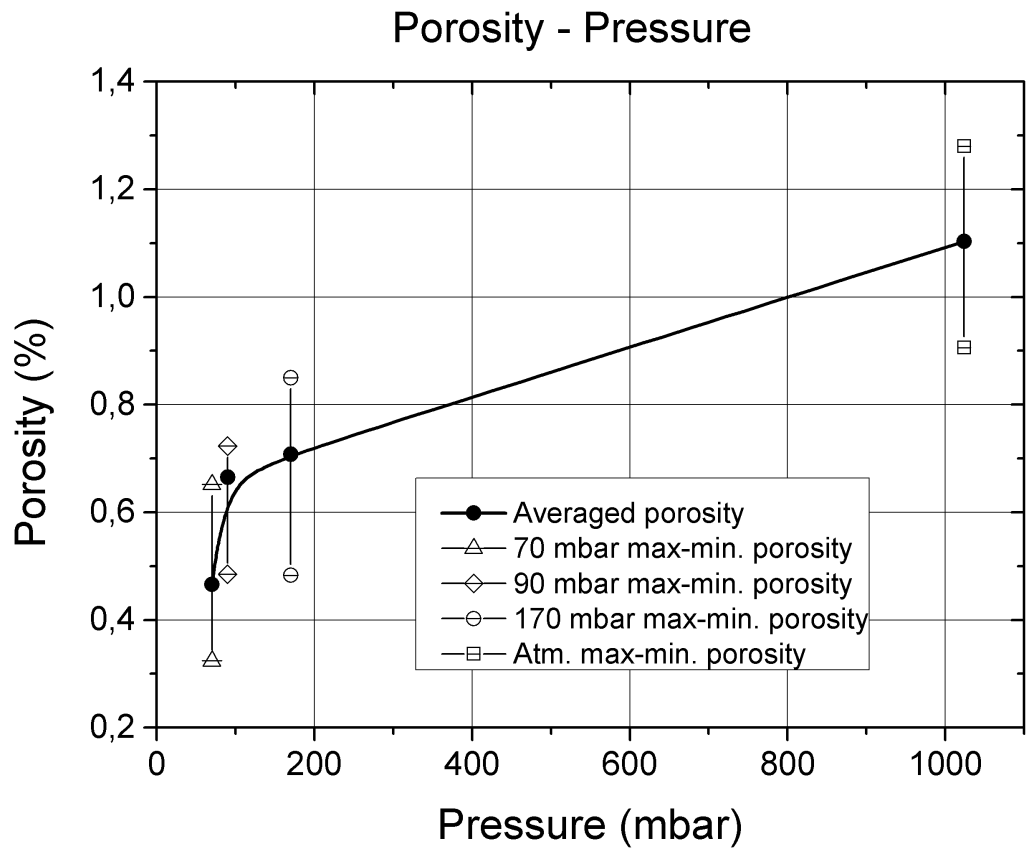

Fig. 7. Specimen volumetric porosity versus pressure curves.

The specimen porosity versus pressure curves shows a significant change in the slope at around 80 mbar. The vacuum-assisted die casting reduces the amount of entrapped air, gases and humidity in the die cavity before injection. The volume of gas porosity was significantly reduced.

\subsection{Mechanical properties}

The three main mechanical properties were investigated: the yield strength $\left(R_{p 0.2}\right)$, the ultimate tensile strength (UTS), and the elongation (A) [34]. At each pressure level 15 specimens were examined by the uniaxial tensile test. The effect of the vacuum-assistance on the mechanical properties are detailed in Table 3 at 50\% and 95\% reliability, respectively. All the measured and tracked mechanical properties were greatly affected by the applied pressure due to the porosity was reduced as the vacuum assistance increased, as mentioned in Section 3.1 .

Table 3. Mechanical properties of the AlSi9Cu3(Fe) on different pressure levels

\begin{tabular}{|l|c|c|c|c|c|c|}
\hline \multirow{2}{*}{$\begin{array}{c}\text { Pressure } \\
\text { (mbar) }\end{array}$} & \multicolumn{2}{|c|}{$\mathrm{R}_{\mathrm{p} 0.2}$ (MPa) } & \multicolumn{2}{c|}{ UTS (MPa) } & \multicolumn{2}{c|}{ A (\%) } \\
\cline { 2 - 7 } & R 50\% & R 95\% & R 50\% & R 95\% & R 50\% & R 95\% \\
\hline $\mathbf{7 0}$ & 170.3 & 167.2 & 299.8 & 291.6 & 2.49 & 2.04 \\
\hline $\mathbf{9 0}$ & 165.6 & 161.7 & 292.2 & 276.3 & 2.16 & 1.63 \\
\hline $\mathbf{1 7 0}$ & 156.5 & 154.0 & 283.9 & 258.4 & 2.14 & 1.43 \\
\hline Atmospheric & 159.2 & 152.9 & 271.6 & 253.7 & 1.66 & 1.31 \\
\hline Atm. (EN1706) & 140 & 140 & 240 & 240 & $<1$ & $<1$ \\
\hline
\end{tabular}

The two-parameter Weibull distribution model at 50\% reliability and 95\% reliability were applied to deal with the variation in mechanical properties of the die cast flat tensile specimen [35]. The different reliability values for the same pressure level did show deviation on the ultimate tensile strength and elongation, while the yield strength values were almost the same. 
The results were plot in a diagram showing the mechanical properties against the pressure (Fig. 8.).

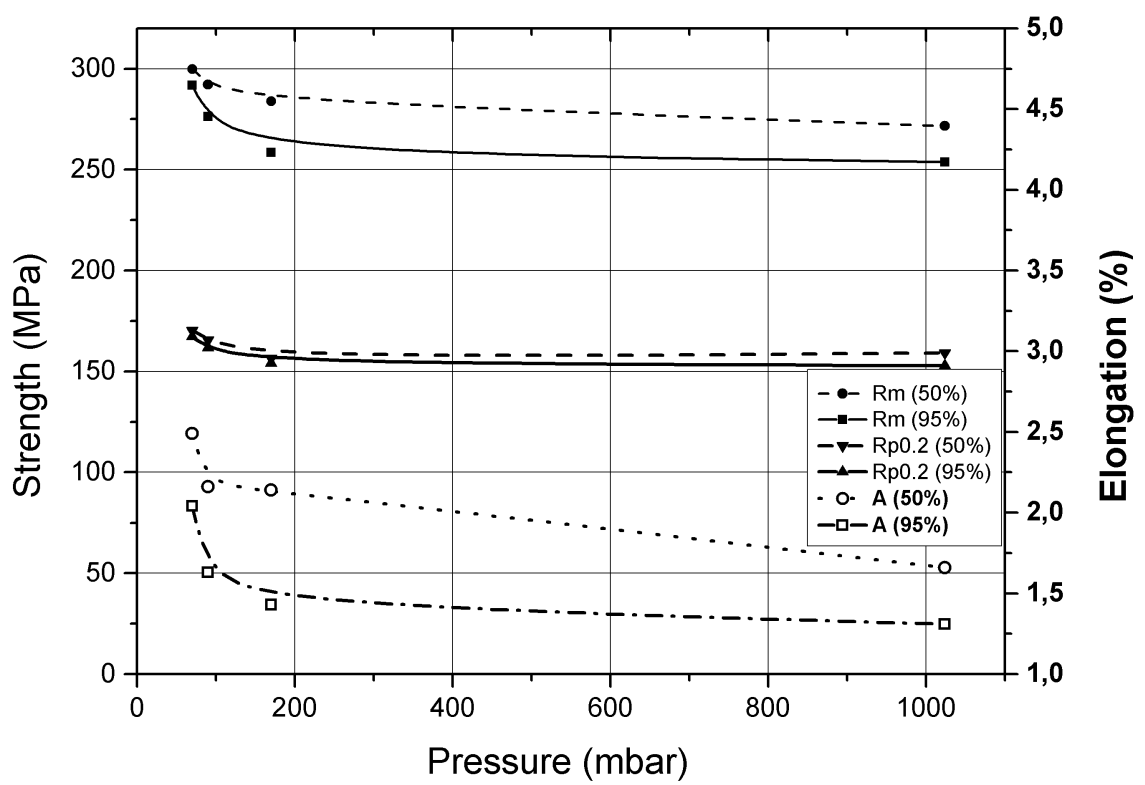

Fig. 8. Mechanical properties versus pressure curves at different reliability.

The reason for the low deviation of the yield strength compared to the 50\% and $95 \%$ reliability levels are in the lower scatter of the values [11]. The strength data are showing remarkable change at around $80 \mathrm{mbar}$, which is similar to the trend in the case of the porosity and pressure curves (Fig. 7).

Due to the pressure change, a marked and emphasized change in the slope of the curve is observed. To avoid the dependency of the casting process parameters, the mechanical properties were plotted as a function of porosity (Fig. 9.). The fitted curve aligned with the displayed points with a linear approximation. 


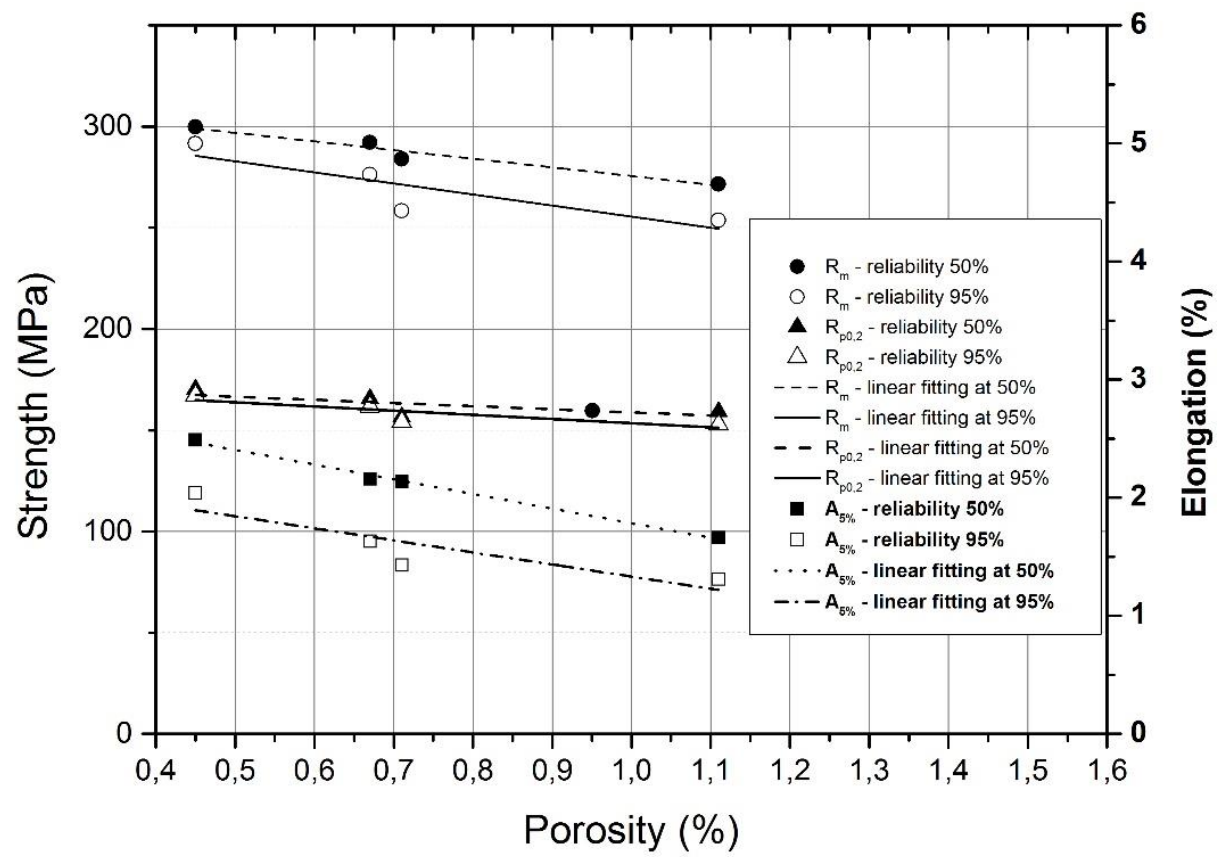

Fig. 9. Mechanical properties as a function of porosity at different reliability.

The equations of the fitted straight lines are written this way (Eq. 4.):

$$
y=m x+b
$$

where $y$ is the mechanical properties in question, $m$ is the slope of the line, $x$ is the required porosity value, and $b$ is the strength intercept;

These equations are valid from porosity $0.4 \%$ to porosity $1.2 \%$, as-casted condition to AlSi9Cu3(Fe) aluminum alloy. The parameters of the fitted straight lines are detailed in Table 4. at $50 \%$ reliability and $95 \%$ reliability, respectively.

Table 4 . The parameters of the fitted straight lines at 50\% and $95 \%$ reliability

\begin{tabular}{|l|c|c|c|c|c|c|}
\hline \multirow{2}{*}{ Parameters } & \multicolumn{2}{|c|}{$\mathrm{R}_{\mathrm{p} 0.2}(\mathrm{MPa})$} & \multicolumn{2}{c|}{ UTS (MPa) } & \multicolumn{2}{c|}{ A (\%) } \\
\cline { 2 - 7 } & $\mathrm{R} \mathrm{50 \%}$ & $\mathrm{R} 95 \%$ & $\mathrm{R} 50 \%$ & $\mathrm{R} 95 \%$ & $\mathrm{R} \mathrm{50 \%}$ & R 95\% \\
\hline b & 174.3 & 174.1 & 318.3 & 310.2 & 3.02 & 2.35 \\
\hline $\mathbf{m}$ & -15.5 & -20.6 & -42.7 & -54.6 & -1.24 & -1.02 \\
\hline
\end{tabular}

The pores can affect significantly the mechanical properties of $\mathrm{AlSi} 9 \mathrm{Cu} 3(\mathrm{Fe})$ aluminum alloy die castings. The vacuum-assisted die casting process can significantly reduce the gas porosity and improve the mechanical properties.

\subsection{Micro- and macrostructure}

The mechanical properties were significantly improved under 100 mbar. These strength increment come from the vacuum pressure change. The cast aluminum alloy was inspected by LOM and SEM. The LOM micrographs of the as-cast condition of the AlSi9Cu3(Fe) alloy are 
illustrated in Figure 10. at different pressure levels. The specimens were sectioned to examine the porosity distribution [36]. The phases present in the metallographic microstructure are mainly $\alpha-\mathrm{Al}$ and the eutectic mixture. The $\alpha-\mathrm{Al}$ phase is a solid solution rich in aluminum, the eutectic consists of alternating layers of $\alpha$-Al phase and silicon plates. As aluminum is soft compared to the silicon, the $\alpha$-Al phase is softer than the eutectic. As it can be seen in the figure, many gas pores were formed during atmospheric pressure. In contrast, the total amount and the size of the gas pores were significantly reduced and showed a uniform distribution in the case of vacuum-assisted die casting.
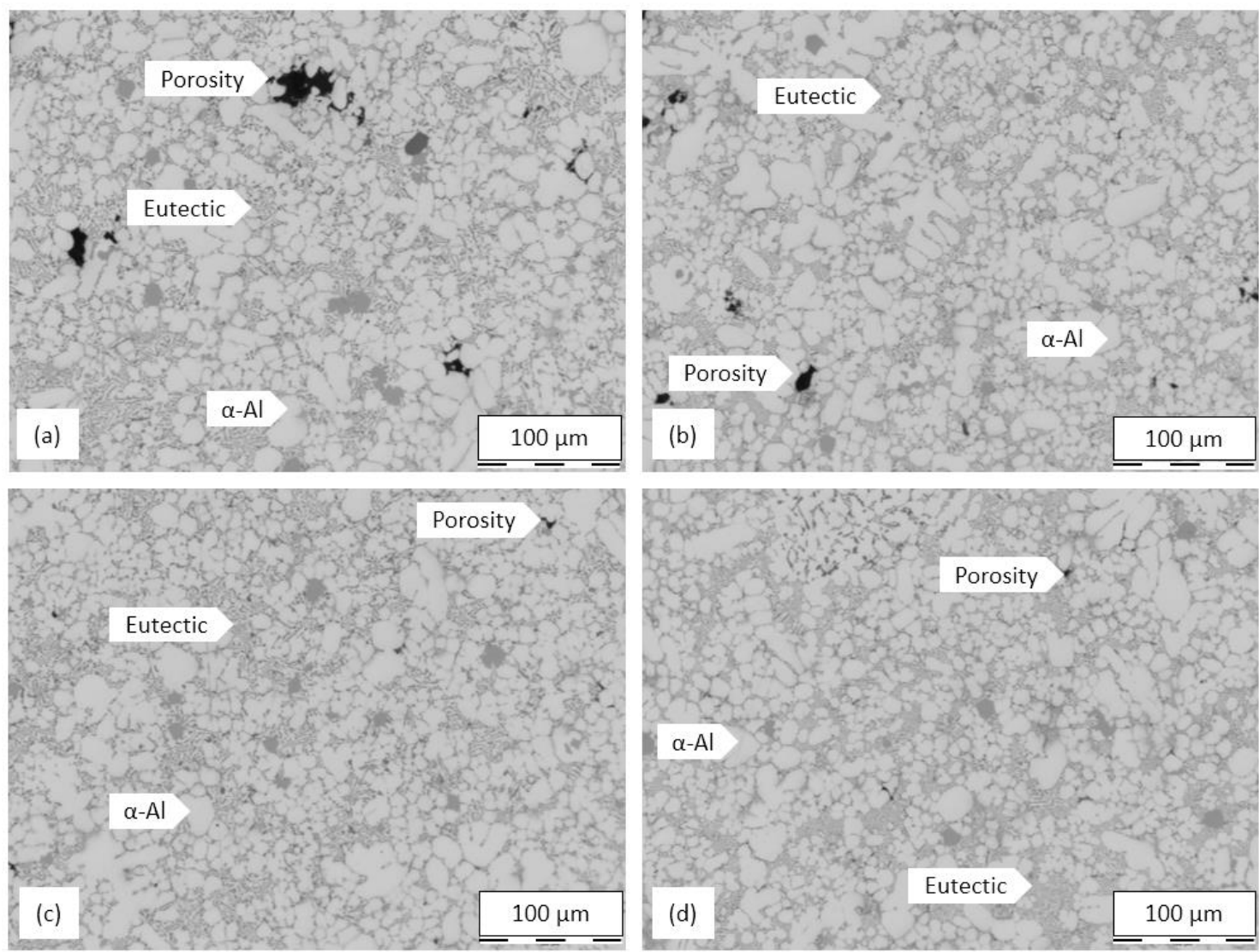

Fig. 10. LOM macrographs of castings showing the morphology and the porosity distribution in: (a) conventional casting and; (b) 170 mbar; (c) 90 mbar and; (d) 70 mbar vacuum-assisted die castings.

The fracture surface was examined by SEM. The samples, which contains aluminum oxide on the fracture surface (Fig. 11.) have been excluded from the evaluation [37]. The internal elements are identified as $\mathrm{Al}, \mathrm{Si}, \mathrm{Cu}$ and $\mathrm{Fe}$ that are consistent with the main component elements of castings (Fig. 12.). The detection of $\mathrm{O}$ element verified the high aluminum oxide content on the fracture surface. The observed internal appearance is irregular and dark gray. The nature of the aluminum oxide is quite same as aluminum alloy depends from the age of the oxide [37] and thin layer shape does not decrease the intensity of the radiation [38], which passes through the material. The aluminum oxide film or flakes act as stress concentrators, that is the reason why these samples have been excluded. 

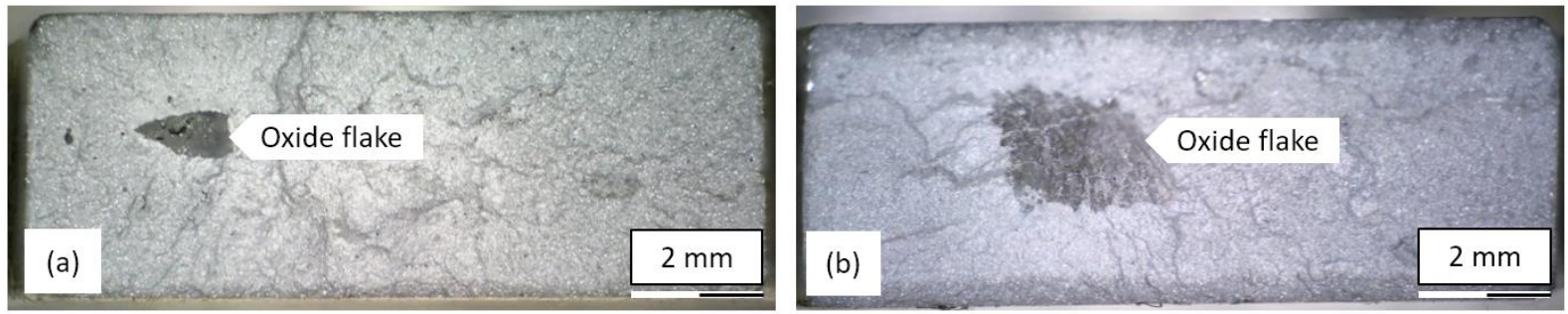

Fig. 11. Aluminum oxide flakes in the fracture surfaces.
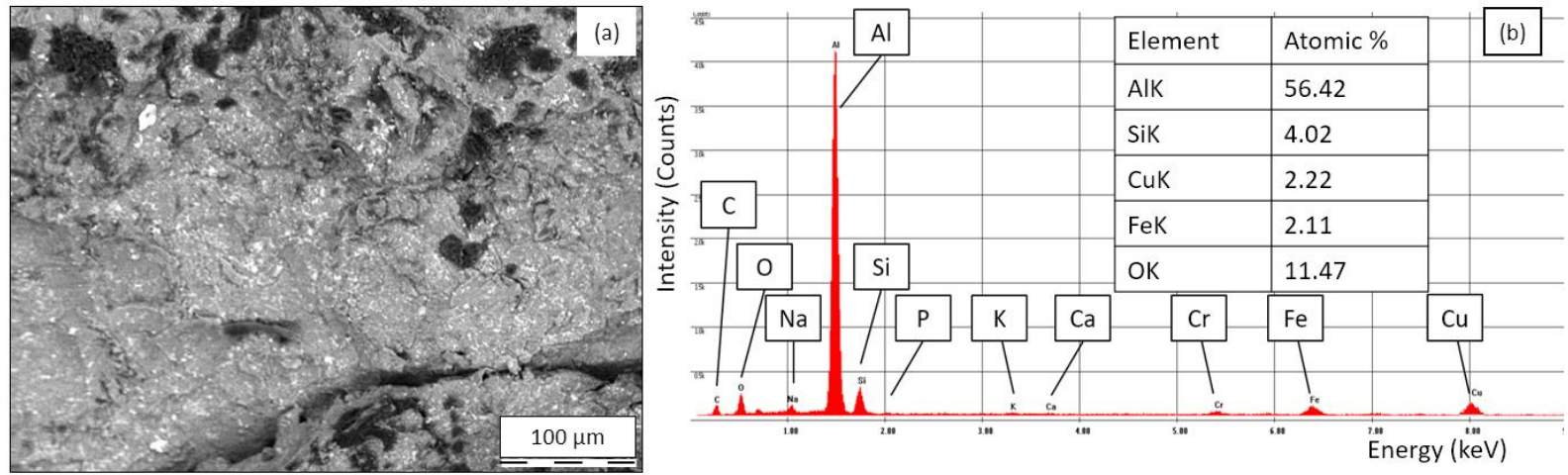

Fig. 12. Internal elements in the fracture surface: (a) aluminum oxide flake by SEM; (b) high oxygen content in the fracture surface by EDX.

Fracture analysis is carried out and the micro appearance of the fracture surface is analyzed by SEM (Fig. 13.) [39]. Aluminum alloys are normally built up from crystals of atoms in the face-centered cubic system, which is the most ductile unit cell. However, the great amount of silicon content creates an eutectic composition, which provides a lower melting point and lower shrinkage. Silicon also causes river pattern strips on the fracture surface. The mixture of the ductile and fracture surfaces shows a quasi-cleavage fracture. In Fig. 11. one can observe that the fracture is quasi-cleavage, which is characterized by river pattern or sharp ridges and bounded by small plate-like areas and dimples. The specimens under lower pressure levels have smaller pores that induce crack initiation and propagation in tensile testing, which may cause that the fracture surface is a quasi-cleavage fracture. The greater stress concentration is produced at the location of larger pores to induce crack initiation. Therefore, the castings under lower absolute pressure are more resistant to break. 

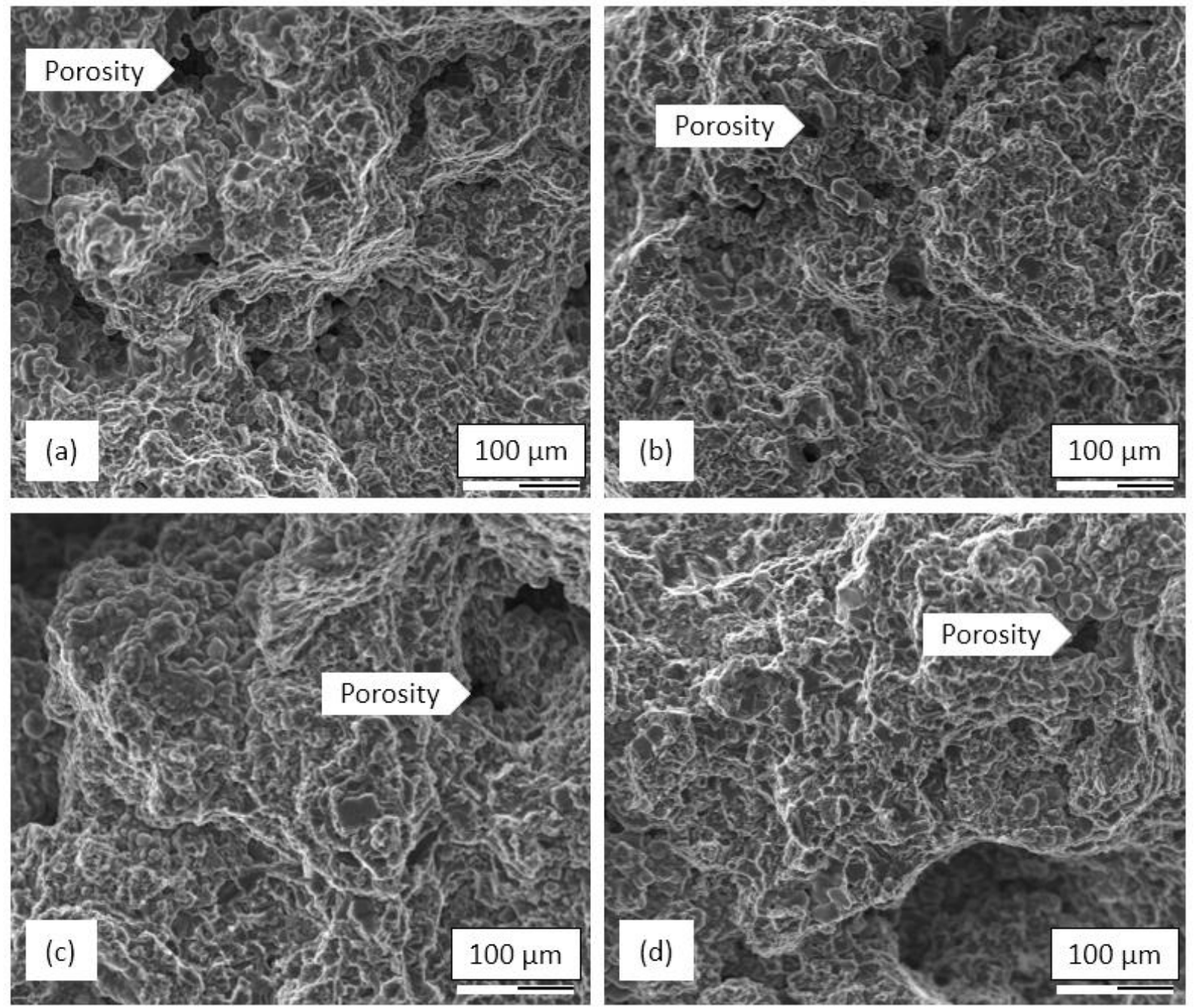

Fig. 13. SEM micrograph of the fracture surface at different absolute pressure: (a) conventional casting and; (b) 170 mbar; (c) 90 mbar and; (d) 70 mbar vacuum-assisted die castings.

The absolute pressure decreases as the shape of the pores changes. The volume of the entrapped gases increases proportionally to the solidification shrinkage of the residual liquid metal in parts. These entrapped gases become the final gas porosities in the die castings [40]. At higher magnification the shape of the pores are proved to be significantly different (Fig. 14.). The shape of the pores is associated with gas entrapment or shrinkage or both together in all castings [41]. The shape of the pores is an important factor in connection with mechanical properties. The pores like a shrinkage with sharp corners are more dangerous stress concentrators than the rounded gas or air pores. During the observation that was found the large pores would easily result in crack initiation and propagation. 

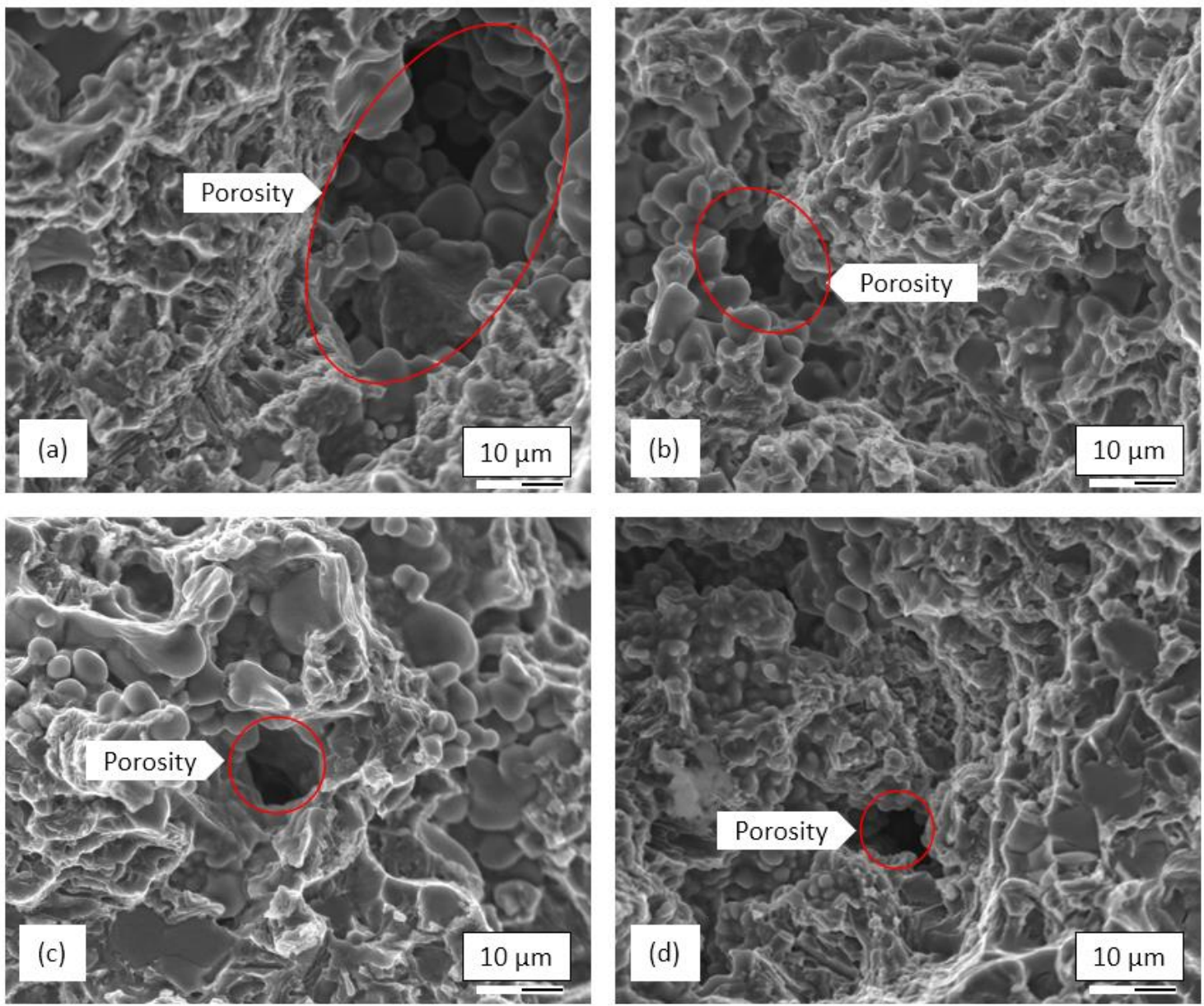

Fig. 14. SEM micrograph of the fracture surface around a pore at different absolute pressure: (a) conventional casting and; (b) 170 mbar; (c) 90 mbar and; (d) 70 mbar vacuum-assisted die castings.

Smooth $\alpha$-Al grains can be observed around the porosity in Fig. 14a., which proves that these pores are shrinkages. The silicon and eutectic also cause river pattern strips and plate-like fracture surfaces in the surrounding areas.

\section{Conclusions}

Both the vacuum-assisted high pressure die casting process and conventional high pressure die casting process were used to produce the standard flat tensile specimens according to ISO 6892-1:2016. The AlSi9Cu3(Fe) die casting aluminum alloy was cast on atmospheric and three different absolute pressure levels of 170 mbar, 90 mbar and 70 mbar. The cast components LOM, SEM and strength results demonstrated that the vacuum-assisted die casting process reduces the amount of entrapped air and other gases in the die cavity and increased the tensile strength and elongation of die casting part.

The effectiveness of vacuum assistance is most pronounced in the absolute pressure range of 80-100 mbar. Based on the data presented in the study the porosity is reduced from $1.10 \%$ at an atmospheric level to $0.47 \%$ at 70 mbar, this corresponds to $57 \%$ reduction. The specimens under lower pressure levels have smaller pores. The vacuum-assisted die casting process can 
significantly reduce the gas porosity and improve the mechanical properties. The improvement

\section{References}

[1] G. Tyler Miller, Jr., Scott E. Spoolman, Living in the Environment, (Cengage Learning, 2011), pp. 396

[2] NADCA, Introduction to die casting. NADCA, (Arlington Heights, Illinois, 2007), pp. 715

[3] Jorstad, J. \& Apelian, D., Pressure Assisted Processes for High Integrity Aluminum Castings, IJMC, 2/1. 19-39. (2008) https://doi.org/10.1007/BF03355420

[4] D. Xixi, Y. Hailin, Z. Xiangzhen, J. Shouxun, High strength and ductility aluminium alloy processed by high pressure die casting, Journals of Alloys and Compounds, 773. 86-96. (2018)

[5] ÖGI, HPDC-technology, Austrian Cooperative Research, Leoben, (2016)

[6] Koru, M. \& Serçe, O., The Effects of Thermal and Dynamical Parameters and Vacuum Application on Porosity in High-Pressure Die Casting of A383 Al-Alloy, IJMC, 12/4. 797-813 (2018) https://doi.org/10.1007/s40962-018-0214-7

[7] A. Zyska, Z. Konopka, M. Lagiewka, M. Nadolski, Porosity of Castings Procedure by the Vacuum Assisted Pressure Die Casting Method, Foundry Engineering, 1. 125-130. (2015)

[8] X. Lia, S.M. Xiong, Z. Guo, Improved mechanical properties in vacuum-assist high pressure die casting of AZ91D alloy, J. Material Process Technol., 1-7. (2016)

[9] Y. Wen-bo, Y. Zi-hao, G. Zhi-peng, X. Shou-mei, Characterization of A390 aluminum alloy procedure at different slow shot speeds using vacuum assisted high pressure die casting, Transactions of Nonferrous Metals Society of China, 27/12. 2529-2538. (2017)

[10] X.P. Niu, B.B. Hu, I. Pinwill, H. Li, Journal of Materials Processing Technology, 105, 119127 (2000)

[11] John Campbell, Castings (Butterworth-Heinemann, Oxford, 2003) 314-318

[12] Dr.-Ing. Werner Hesse, Key to Aluminium Alloys (Aluminium-Verlag, Düsseldorf; 2008) p. 88 
[13] Abdel Illah Nabil Korti, Said Abboudi, Effects of Shot Sleeve Filling on Evolution of the

(2017) DOI 10.1007/s40962-016-0051-5

[14] Thoma, C., Volk, W., Heid, R. et al., Simulation-Based Prediction of the Fracture Elongation as a Failure Criterion for Thin-Walled High-Pressure Die Casting Components, IJMC, 8/4. 47-54. (2014) https://doi.org/10.1007/BF03355594

[15] ISO 6892-1:2016: Metallic materials - Tensile testing - Part1, Method of test at room temperature, (2016)

[16] BN-75/4051-10: Porosity of Casting by hydrostatic weighing, (1975)

[17] N.A. Pratten.; The precise measurement of the density of small samples, J. Mater. Sci. 16 7, 1737-1747 (1981)

[18] Z. Shiwei, S. Kun, H. Feng, Z. Fan, A new dropper-type gas flow measuring method based on weighing principle, Vacuum, 145. 203-208. (2017)

[19] R. Hayu, H. Sutanto, Z. Ismail, Accurate density measurement of stainless steel weights by hydrostatic weighing system, Measurement, 131. 120-124. (2019)

[20] EN 1706:2013-12: Aluminium and aluminium alloys - Castings: Chemical composition and mechanical properties, (2013)

[21] ITS-90 Density of Water Formulation for Volumetric Standards Calibration, Journal of Research of the National Institute of Standards and Technology, 97, 3, 336-340. (1992)

[22] C. Maierhofer, P. Myrach, M. Röllig, F. Jonietz, B. Illerhaus, D. Meinel, U. Richter, R. Miksche, Characterization of Pores in High Pressure Die Cast Aluminum Using Active Thermography and Computed Tomography, $42^{\text {nd }}$ Annual Review of Progress in Quantitative Nondestructive Evaluation, 1-8. (2016)

[23] A. Rotella, Y. Nadot, M. Piellard, R. Augustin, M. Fleuriot, Fatigue limit of a cast Al-SiMg alloy (A357-T6) with natural casting shrinkages using ASTM standard X-ray inspection, International Journal of Fatigue, 114. 177-188. (2018)

[24] ASTM E505-15: Standard Reference Radiographs for Inspection of Aluminum and Magnesium Die Castings, (2015)

[25] U. Richter, S. Arendholz, R. R. Miksche, M. Rölling, C. Maierhofer, K. Eigenfeld, Porosity detection in high pressure die castings, International Foundry Research, 1. 14-23. (2015)

[26] A. Niklas, A. Bakedano, S. Orden, M. da Silva, E. Nogués, A. I. Fernández-Calco, Effect of Microstructures and Casting Defects on the Mechanical Properties of Secondary AlSi10MnMg(Fe) Test Parts Manufactured by Vacuum Assisted High Pressure Die Casting Technology, Materialstoday Proceedings, 2/10. 4931-4938. (2015)

[27] M. Wicke, A. Brueckner-Foit, T. Kristen, M. Zimmermann, F. Buelbuel, H.-J. Christ, Near-threshold crack extension mechanism in an aluminum alloy studied by sem and X-ray tomography, International Journal of Fatigue, 113. 87-98. (2018) 
[28] Asghar Azizi; Investigation the controllable factors influencing the weight loss of grinding ball using SEM/EDX analysis and RSM model, Engineering Science and Technology, an International Journal, 18. 278-285. (2015)

[29] A. Siot, C. Longuet, R. Léger, B. Otazaghine, P. Lenny, A.-S. Cari-Bretelle, N. Azéma, Correlation between process and silica dispersion/distribution into composite: Impact on mechanical properties and Weibull statistical analysis, Polymer Testing, 70. 92-101. (2018)

[30] C. Hanxue, H. Mengyao, S. Chao, L. Peng, The influence of different vacuum degree on the porosity and mechanical properties of aluminum die casting, Vacuum, 146. 278-281. (2017)

[31] X.G. Hu, Q. Zhu, S.P. Midson, H.V. Atkinson, H.B. Dong, Z. Zhang, Y.L. Kang, Blistering in semi-solid die casting of aluminum alloys and its avoidance, Acta Materialia, 124. 446-455. (2017)

[32] Q. Mingfan, K. Yonglin, T. Wenchuan, Q. Quanquan, L. Baoshun, Mictrostructure, mechanical properties and corrosion behavior of Rheo-HPDC a novel Al-8Si-Fe alloy, Materials Letters, 213. 378-382. (2018)

[33] H. Qiyao, Z. Haidong, L. Fangdong, Microstructures and properties of SiC particles reinforced aluminum-matrix composites fabricated by vacuum-assisted high pressure die casting, Material Science and Engineering: A, 680. 270-277. (2017)

[34] D. Bin, J. Danyu, G. Jianghong, Is a three-parameter Weibull function really necessary for the characterization of the statistical variation of the strength of brittle ceramics?, Journal of the European Ceramic Society, 38/4. 2234-2242. (2018)

[35] A.H. Shevidi, R. Taghiabadi, A. Razaghian, Weibull analysis of effect of T6 heat treatment on fracture strength of AM60B magnesium alloy, Transactions of Nonferrous Metals Society of China, 28/1. 20-29. (2018)

[36] M.V.Santosh, K.R. Suresh, S. Kiran Aithal, Mechanical Characterization and Microstructure analysis of Al C355.0 by Sand Casting, Die Casting and Centrifugal Casting Techniques, Materialstoday Proceedings, 4/10. 10987-10993. (2017)

[37] Kittiphan Bangyikhan, Effect of Oxide film, Fe-rich phase, Porosity and their Interactions on Tensile Properties of Cast Al-Si-Mg Alloys (PhD thesis of the Faculty of Engineering of The University of Birmingham, 2005) pp. 45.

[38] David C. Jiles, Introduction to the Principles of Materials Evaluation, Wolfson Center for Magnetic, (Institute for Advanced Materials and Energy Systems, Cardiff University, U.K., 2007) pp. 79-97

[39] John Campbell, Xinjin Cao, Oxide inclusion defects in Al-Si-Mg cast alloys, Canadian Metallurgical Quarterly, 435-447. (2005)

[40] Yalçin, B., Koru, M., Ipek, O. et al., Effect of Injection Parameters and Vacuum on the Strength and Porosity Amount of Die-Casted A380 Alloy, IJMC, 11/2. 195-206 (2017) https://doi.org/10.1007/s40962-016-0046-2

[41] Z. Lijie, Y. Bing, F. Jian, K. Xiangyang, J. Haiyan, D. Wenjiang, Microstructure tensile properties and creep behavior of $\mathrm{Al}-12 \mathrm{Si}-3.5 \mathrm{Cu}-2 \mathrm{Ni}-0.8 \mathrm{Mg}$ alloy produced by different casting technologies, Journal of Materials Science \& Technology, 34/7. 1222-1228. (2018) 